\title{
Maternal risk factors and perinatal outcomes among pacific islander groups in Hawaii: a retrospective cohort study using statewide hospital data
}

\author{
Ann Lee Chang ${ }^{1 *}$, Eric Hurwitz ${ }^{2}$, Jill Miyamura ${ }^{3}$, Bliss Kaneshiro ${ }^{1}$ and Tetine Sentell ${ }^{2}$
}

\begin{abstract}
Background: Studies suggest Pacific Islander women have disparate rates of preterm birth, primary cesarean delivery, preeclampsia, gestational diabetes, and low birthweight infants. However, data is limited. In order to improve the health of Pacific Islanders, it is essential to better understand differences in obstetric outcomes in this diverse population

Methods: This study compared perinatal outcomes between Pacific Islander $(9,646)$ and White $(n=5,510)$ women who delivered a singleton liveborn in any Hawaii hospital from January 2010 to December 2011 using the Hawaii Health Information Corporation (HHIC) database. Pacific Islanders were disaggregated into the following groups: Native Hawaiian, Samoan, Micronesian, and Other Pacific Islanders. Perinatal outcomes (e.g. hypertensive diseases, birthweight, mode of delivery) were compared using multivariable logistic models controlling for relevant sociodemographic and health risk factors (e.g. age and payer type).

Results: Significant differences in perinatal outcomes between Pacific Islander and White women and newborns were noted. All Pacific Islander groups had an increased risk of hypertension. Outcome differences were also seen between Pacific Islanders groups. Native Hawaiians had the highest risk of low birthweight infants, Samoans had the highest risk of macrosomic infants and Micronesians had the highest risk of cesarean delivery.

Conclusions: Important differences in perinatal outcomes among Pacific Islanders exist. It is important to examine Pacific Islander populations separately in future research, public health interventions, and policy.
\end{abstract}

Keywords: Pregnancy outcomes, Pacific Islander Americans, Hawaii

\section{Background}

Pacific Islanders, including Native Hawaiians, Samoans, and Micronesians, comprise an important and rapidly increasing proportion of the United States (US) population [1]. These groups are adversely affected by socioeconomic disparities that are known to result in a higher risk of adverse obstetric outcomes [2-4]. Indeed, studies in both the US and New Zealand suggest that Pacific Islander women have disparate rates of preterm birth, primary cesarean delivery, preeclampsia, gestational

\footnotetext{
* Correspondence: annchang@hawaii.edu

'Department of Obstetrics, Gynecology and Women's Health, University of Hawaii, 1319 Punahou Street Suite \#824, Honolulu, HI 96826, USA Full list of author information is available at the end of the article
}

diabetes, and low birthweight, but data in these groups is extremely limited [5-13]. Most studies on this topic aggregate Asian and Pacific Islander women into a single large group [5-7]. The few studies that disaggregate Pacific Islanders from Asian subgroups did not explore Pacific Islander subgroups separately; $[8,12]$ focused on only one hospital in one location; $[8,13]$ or only examined a few outcomes $[9,10,12-15]$. In order to improve the health of Pacific Islanders, it is essential to understand differences in obstetric outcomes in Pacific Islander subgroups residing in the United States.

The goal of this study was to quantify obstetric outcomes across Pacific Islander subgroups residing in Hawaii. According to the 2010 US Census, Hawaii 
has highest proportion of residents who report being Native Hawaiians or Pacific Islanders; $23 \%$ of all Pacific Islanders in the US live in Hawaii [1]. We selected common outcomes with well-established morbidity including diabetes, hypertension, cesarean delivery, and birthweight. [14-20]

\section{Methods \\ Sample}

The Hawaii Health Information Corporation (HHIC) inpatient database was used to conduct this study. The HHIC Mothers and Babies Database includes all maternal delivery and live newborn hospital admissions in the state of Hawaii. Demographic information (such as race and payer type), up to twenty International Classification of Diseases, 9th Revision (ICD-9) diagnosis codes per patient, and up to twenty ICD-9 procedure codes per patient are included in the database. The HHIC is Hawaii's healthcare data organization participating with the Agency for Healthcare Research and Quality (AHRQ) Healthcare Cost and Utilization Project, which is a Federal-State-Industry partnership sponsored by AHRQ [21, 22]. We received permission from HHIC to use their Mothers and Babies Database for the purpose of this study.

Our study population consisted of all Pacific Islander and White women who delivered a singleton liveborn in any Hawaii hospital from January 2010 to December 2011 and their newborns. All non-federal acute care hospitals in Hawaii were included. Women with ICD-9 codes corresponding to multiple gestations were excluded. There were 36,683 maternal delivery admissions for singleton liveborns in Hawaii during time period studied; 5,510 persons were White and 9,646 were Pacific Islanders. Thus, the study sample was 15,156 .

All data were de-identified and the analysis was deemed exempt by the Institutional Review Board of the University of Hawaii under federal exemption category 4.

\section{Variables}

Race was based on self-report by each patient at time of admission. Thirteen of the 34 possible races represented in the database are part of the Pacific Islander category. Women were classified as based on the most commonly reported Pacific Islander races in our population: Native Hawaiian (Native Hawaiian, Hawaiian, and Part Native Hawaiian); Micronesian (Marshallese, Other Micronesian, Guamanian or Chamorro); Samoan; and Other Pacific Islander (all other Pacific Islander categories). Those classified as Whites were used as the comparison group.

Other maternal demographic data obtained from the database included age (in years), payer type, and admission to a rural hospital versus urban hospital. These sociodemographic risk factors were chosen given their association with disparate obstetric outcomes [3, 7, 23-30]. Payer type was separated into private versus public/ uninsured (Medicaid, Medicare, and uninsured). The uninsured subjects were combined with the Medicaid and Medicare subjects as both populations are similar in economic status; per the Kaiser Family Foundation, $74 \%$ of the uninsured nonelderly in Hawaii are eligible for either Medicaid or via the Marketplaces; $9 \%$ are immigrants that are not eligible for government-funded insurance due do their immigration status [31].

Perinatal outcomes were obtained by extracting ICD-9 codes from each admission. Variables included hypertension (pre-existing and pregnancy-associated hypertension), diabetes mellitus (pre-gestational and gestational), and mode of delivery (vaginal or cesarean delivery). Additional file 1 contains the ICD-9 codes used to identify these diagnoses. We chose the ICD-9 codes for these outcomes based on a prior validation study by Yasmeen et al. [32] Although their sensitivity for cesarean delivery was $100 \%$, we also included the newborn ICD-9 codes of v3xx.1 (newborn born via cesarean); by doing so we identified 34 additional women who had a cesarean. Yasmeen et al. found that the sensitivity for the ICD-9 codes for pre-gestational diabetes and gestational diabetes were 75 and $64 \%$, respectively, and the codes for chronic hypertension and pregnancy-related hypertension were 58 and $88 \%$, respectively. However, by combining pre-gestational and gestational diabetes into a broader category of diabetes and doing the same for hypertensive diseases, the sensitivities should be more reliable [33].

Newborns were separated into categories of low birthweight $(<2500 \mathrm{~g})$, normal weight $(2500-4000 \mathrm{~g})$ and macrosomic ( $>4000 \mathrm{~g})$.

\section{Statistical analyses}

Data were analyzed using JMP 11.1.1 [34] and SPSS version 21 [35]. Obstetric outcomes and demographics were compared among Pacific Islander subgroups and with Whites. Whites were used as the reference group because of the common use of this group in examining racial disparities. The study population was first summarized using descriptive statistics. Chi square tests were used to calculate $\mathrm{p}$ values. Multivariable logistic regression models were then created to explore the association between racial group and obstetric outcome. Potential confounders such as maternal demographics and risk factors were included in the model. Demographic variables included in all models were: age, race, delivery at a rural versus urban hospital, and payer type. Other specific variables in the multivariable logistic models varied by outcome. Variables were chosen because of their known associations with the examined outcomes based 
on previous published research and/or because multivariate models from other comparison studies have included them [7-20, 23-30, 36-39]. Adjusted odds ratios (aORs) and $95 \%$ confidence intervals (CIs) were obtained for each outcome using these models. Statistical significance was set at $P<0.05$.

\section{Results}

Differences were seen in all demographic factors and perinatal outcomes across Pacific Islander subgroups and Whites (Table 1). Teen births were more common in all Pacific Islander subgroups compared to Whites. The percentage of deliveries by women of advanced maternal age was highest in Whites. The proportion of women who delivered in a rural versus an urban hospital was significantly different by maternal race. More than $40 \%$ of Whites compared to $5.9 \%$ of Samoans delivered in a rural hospital. Approximately one-third of Whites (31.7\%) had public insurance or no insurance whereas more than $50 \%$ of Pacific Islanders had this insurance type, with the highest percentage being $88.3 \%$ for Micronesians.

Whites had the lowest prevalence of diabetes and hypertension. Diabetes was most prevalent among Other Pacific Islanders (13.7 \%) and Samoans (12.6 \%). Samoans (14.9\%) and Native Hawaiians (11.9\%) had the highest rates of hypertension.
Delivery mode and birthweight varied across all groups studied. Cesarean section rates were highest for Micronesians $(32.3 \%)$ and lowest for Samoans (21.1\%). Samoans also had babies with the highest mean birthweight, the highest rates of macrosomia (birthweight greater than $4000 \mathrm{~g})$, and the lowest rates of low birthweight $(<2500 \mathrm{~g})$. Low birthweight was highest among Native Hawaiians and Other Pacific Islanders, 7.3 and $7.1 \%$ respectively, compared to $4.1 \%$ for Samoans.

\section{Multivariable analyses}

Results of the multivariate regression analyses with Whites as the comparison group are shown in Table 2.

All Pacific Islander subgroups had significantly higher (at least two-fold) adjusted odds ratios for diabetes compared to Whites. Similarly, all Pacific Islander subgroups other than Micronesians had significantly higher adjusted odds ratios for hypertension compared to Whites; Samoans and Native Hawaiians had the highest adjusted odds ratios (aOR 1.63; 95 \% CI 1.31-2.04 and aOR 1.62; 95 \% CI 1.42-1.84, respectively).

Native Hawaiians had the highest, statistically significant adjusted odds ratio (aOR 1.16; $95 \%$ CI 1.01-1.34) for low birthweight babies. Samoans, on the other hand, were significantly less likely to have low birthweight infants than Whites (aOR 0.55; $95 \%$ CI 0.40-0.76). Samoans were also more likely than Whites to have

Table 1 Maternal demographics and outcomes among singleton births, Hawaii, 2010-2011 by race/ethnicity. (HHIC Inpatient Data, 2010-2011)

\begin{tabular}{|c|c|c|c|c|c|c|}
\hline & Native Hawaiian & Micronesian & Samoan & Other Pacific Islanders & White & p-value \\
\hline $\mathrm{n}$ & 6662 & 1548 & 897 & 539 & 5510 & \\
\hline \multicolumn{7}{|l|}{ Demographics } \\
\hline Delivery in rural hospital (\%) & $2621(39.3)$ & $478(30.9)$ & $53(5.9)$ & $53(28.9)$ & $2254(40.9)$ & $<.0001$ \\
\hline Public insurance/uninsured (\%) & $3658(54.9)$ & $1367(88.3)$ & $594(66.2)$ & $324(60.1)$ & $1746(31.7)$ & $<.0001$ \\
\hline Mean age (years) (SD) & $26.4(6.1)$ & $26.4(5.5)$ & $26.3(5.9)$ & $27.6(6.3)$ & $29.4(6.0)$ & $<.0001$ \\
\hline \multicolumn{7}{|l|}{ Age Groups } \\
\hline$<20$ years $(\%)$ & $846(12.7)$ & $127(8.2)$ & $106(11.8)$ & $44(8.2)$ & $250(4.5)$ & $<.0001$ \\
\hline$>35$ years $(\%)$ & $724(10.9)$ & $140(9.0)$ & $91(10.1)$ & $84(15.6)$ & $1100(20.0)$ & $<.0001$ \\
\hline \multicolumn{7}{|l|}{ Outcomes } \\
\hline Diabetes (\%) & $621(9.3)$ & $132(8.5)$ & $113(12.6)$ & $74(13.7)$ & $319(5.8)$ & $<.0001$ \\
\hline Hypertension (\%) & $792(11.9)$ & $145(9.4)$ & $134(14.9)$ & $64(11.9)$ & $413(7.5)$ & $<.0001$ \\
\hline \multicolumn{7}{|l|}{ Mode of Delivery } \\
\hline Cesarean delivery (\%) & $1671(25.1)$ & $500(32.3)$ & $189(21.1)$ & $163(30.2)$ & $1474(26.8)$ & $<.0001$ \\
\hline Primary cesarean (\%) & $808(12.1)$ & $273(17.6)$ & $90(10.0)$ & $83(15.4)$ & $871(15.8)$ & $<.0001$ \\
\hline Vaginal delivery (\%) & $4991(74.9)$ & $1048(67.7)$ & 708 (78.9) & $376(69.8)$ & $4036(73.3)$ & $<.0001$ \\
\hline \multicolumn{7}{|l|}{ Birthweight } \\
\hline Mean birthweight in grams (SD) & $3264(586)$ & $3219(550)$ & $3477(618)$ & $3372(609)$ & $3368(543)$ & $<.0001$ \\
\hline$<2500$ grams (\%) & $489(7.3)$ & $106(6.9)$ & $37(4.1)$ & $38(7.1)$ & $266(4.8)$ & $<.0001$ \\
\hline$>4000$ grams (\%) & $504(7.6)$ & $91(5.9)$ & $140(15.6)$ & $62(11.5)$ & $540(9.8)$ & $<.0001$ \\
\hline
\end{tabular}


Table 2 Unadjusted and adjusted odds ratios (95\% confidence intervals) for perinatal outcomes of Pacific Islander subgroups compared to Whites (HHIC Inpatient Data, 2010-2011)

\begin{tabular}{|c|c|c|c|c|c|}
\hline & Diabetes & Hypertension & Low birthweight <2500 grams & Macrosomia $>4000$ grams & Cesarean delivery \\
\hline & OR $(95 \% \mathrm{Cl})$ & OR $(95 \% \mathrm{Cl})$ & OR $(95 \% \mathrm{Cl})$ & OR $(95 \% \mathrm{Cl})$ & OR $(95 \%$ Cl) \\
\hline \multicolumn{6}{|l|}{ Native Hawaiian } \\
\hline Unadjusted OR & $1.68(1.46-1.93)$ & $1.60(1.42-1.81)$ & $1.56(1.34-1.82)$ & $0.75(0.66-0.86)$ & $0.91(0.85-0.99)$ \\
\hline Adjusted OR & $2.22(1.92-2.57)$ & $1.62(1.42-1.84)$ & $1.16(1.01-1.34)$ & $0.84(0.74-0.96)$ & $0.93(0.85-1.01)$ \\
\hline \multicolumn{6}{|l|}{ Micronesian } \\
\hline Unadjusted OR & $1.52(1.24-1.87)$ & $1.21(0.99-1.47)$ & $1.45(1.15-1.83)$ & $0.57(0.46-0.72)$ & $1.31(1.16-1.48)$ \\
\hline Adjusted OR & $1.98(1.58-2.49)$ & $1.09(0.88-1.34)$ & $1.08(0.87-1.35)$ & $0.67(0.53-0.86)$ & $1.35(1.19-1.54)$ \\
\hline \multicolumn{6}{|l|}{ Samoan } \\
\hline Unadjusted OR & $2.30(1.84-2.88)$ & $2.00(1.62-2.47)$ & $0.85(0.60-1.21)$ & $1.70(1.39-2.08)$ & $0.73(0.61-0.87)$ \\
\hline Adjusted OR & $2.63(2.06-3.35)$ & $1.63(1.31-2.04)$ & $0.55(0.40-0.76)$ & $1.87(1.51-2.32)$ & $0.92(0.77-1.09)$ \\
\hline \multicolumn{6}{|c|}{ Other Pacific Islander } \\
\hline Unadjusted OR & $2.49(1.91-3.25)$ & $1.71(1.31-2.23)$ & $1.50(1.05-2.13)$ & $1.19(0.90-1.58)$ & $1.87(0.98-1.44)$ \\
\hline Adjusted OR & $2.82(2.13-3.72)$ & $1.50(1.14-1.98)$ & $1.20(0.88-1.64)$ & $1.23(0.93-1.64)$ & $1.31(1.08-1.59)$ \\
\hline Whites & 1.00 & 1.00 & 1.00 & 1.00 & 1.00 \\
\hline
\end{tabular}

Adjusted for age, rural, insurance

In addition

-Diabetes: already adjusted for hypertension

-Hypertension: also adjusted for diabetes

-Low birthweight and macrosomia: also adjusted for diabetes and hypertension

-Cesarean delivery: also adjusted for diabetes, hypertension, birthweight

macrosomic infants (aOR 1.87; $95 \%$ CI 1.51-2.32), while Native Hawaiians and Micronesians were significantly less likely to have macrosomic infants compared to Whites (aOR 0.84; $95 \%$ CI 0.74-0.96 and aOR 0.67; 95 \% CI 0.53-0.83, respectively).

Compared to Whites, Micronesians and Other Pacific Islanders were more likely to have cesarean deliveries (aOR 1.35; 95 \% CI 1.19-1.454 and aOR 1.31; 95 \% CI $1.08-1.59$, respectively). Samoans and Native Hawaiians were less likely than Whites to have a cesarean in the unadjusted model but these findings were not significant in the adjusted model.

\section{Discussion}

This study revealed that, compared to Whites, Pacific Islanders in Hawaii generally had more socioeconomic and demographic risk factors such as teen birth and having public or no insurance. These factors are known predictors of adverse obstetric outcomes [25-28]. Thus it is not surprising that all Pacific Islander subgroups studied were more likely to have diabetic disease and all Pacific Islander groups except for Micronesians were more likely to have hypertensive disorders.

However, Pacific Islanders also showed considerable variation between subgroups in perinatal outcomes when examining birthweight and cesarean delivery. Whites did not have better outcomes than all the Pacific Islander groups studied, nor did one Pacific Islander subgroup fare better or worse than the other subgroups in these outcomes. For example, when compared to Whites, Samoans were less likely to have low birthweight infants whereas Native Hawaiians were more likely to have low birthweight infants. Regarding mode of delivery, Micronesians were more likely to have a Cesarean delivery while the other Pacific Island groups were not at increased or decreased risk for Cesarean delivery compared to Whites. Many of these variations have not been shown in previous research due to limited sample sizes of disaggregated Pacific Islander groups.

Our study confirmed some findings that were seen in previous studies, such as the high teen birth rates of $\mathrm{Pa}-$ cific Islanders [40]. The higher adjusted odds ratio for low birthweight infants among Native Hawaiians is also consistent with prior research $[10,11]$. Our prevalence of diabetic disease among Micronesians is similar to that found in an earlier study on gestational diabetes among Micronesians in Hawaii [41]. The high rates of macrosomic infants among Samoans have also been noted in the literature $[11,13]$.

Although Samoans had the highest prevalence and highest risk of delivering macrosomic infants, they did not have an increased risk of cesarean delivery. Micronesians, on the other hand, had infants with the lowest mean birthweight and the lowest risk of delivering a macrosomic infant yet experienced the highest risk of cesarean delivery.

Anthropometric differences in race/ethnicity may help explain these findings. One would expect Samoans to 
have an increased risk for cesarean, due to their higher rates of hypertensive and diabetic diseases as well as obesity [42]. According to the Centers for Disease Control and Prevention's Pregnancy Risk Assessment Monitoring System (PRAMS), Samoans had the highest prevalence of pre-conception overweight and obesity compared to all other ethnic groups studied, followed by Other Pacific Islanders (non-Hawaiians) [43].

This is the largest study using detailed hospital data to examine obstetric outcomes of Pacific Islanders in the United States. Furthermore, this is the largest study examining obstetric outcomes of Micronesians, a rapidly growing population in both the Hawaii and the United States [44]. Because all Hawaii hospitals except for the military hospital were included in this study, our findings are representative of the entire civilian Pacific Islander population in Hawaii.

However, there are several limitations of the study. Only the largest Pacific Islander groups were studied. There is likely heterogeneity within the Other Pacific Islander subgroup and possibly within the other Pacific Islander groups studied here as well. Sample size and hospital classification methods limited studying smaller subgroups separately. The White population in Hawaii (a minority population in Hawaii) may not be representative of the White population in the US $[45,46]$.

All variables other than age, delivery in rural hospital, birthweight, and insurance status were extracted from ICD-9 codes. Data on some risk factors and potential confounders were not readily available, or were not reliably reported, from discharge ICD-9 codes in the HHIC inpatient database. Thus our models are missing such critical factors as parity, body mass index, tobacco use, education, and early access to prenatal care. These factors, especially parity and body mass index, would have likely impacted results in the multivariate models. Linking our database to birth certificate data or gathering this detailed clinical data from hospital charts would be a fruitful area for future research. Furthermore, this would allow us to study other key perinatal outcomes such as preterm delivery, which is underreported when using ICD-9 codes [47].

This study reveals several important clinical, public health and policy implications. Understanding Pacific Islanders' specific perinatal risks, clinicians will be able to better counsel and manage their pregnant patients. Because teen birth is associated with poorer medical, social, and economic outcomes for teen mothers and their children, there should be further studies and interventions to assess attitudes towards teen pregnancy, explore the reasons for teen pregnancy, and to assist teenage mothers in all Pacific Islander populations [25, 48-51]. Given that the majority of each Pacific Islander subgroup rely on public insurance or are uninsured, policy should be created to improve access to health care and to improve health care delivery and utilization within the public system.

Pre-existing and gestational hypertensive and diabetic diseases in pregnancy have not only immediate consequence (e.g. congenital anomalies, premature delivery) but also have potential long-term sequelae (renal insufficiency, cardiovascular disease) [34-37]. The disparate rates of these conditions among Pacific Islanders should be investigated further. The barriers and facilitators to prevention and care for these condition among each Pacific Islander population need to be better understood before developing initiatives to educate and support Pacific Islander groups and their health care providers. The impact of the obesity epidemic on these conditions as well as all other perinatal outcomes among Pacific Islander groups should be further studied.

Additional studies and public health interventions should address each population's specific areas of need. This study identifies many of these for specific Pacific Islander groups. For example, given the higher rates of morbidity for cesarean deliveries compared to vaginal deliveries, as well as societal costs for cesarean deliveries, efforts should be made to decrease the rates of cesarean deliveries for Micronesians. In order to do this, additional studies should be conducted to better understand Micronesians' increased odds of cesarean deliveries. Likely obesity is playing a factor.

And most importantly, interventions and policy should address the heterogeneity of the Pacific Islander groups and the different settings in which they receive health care. Language and other cultural differences need to be considered. Discrimination likely plays a role in some of these disparities and when present, they should be addressed [52-54].

\section{Conclusions}

Important differences in risk factors for poor obstetric outcomes and in perinatal outcomes among Pacific Islanders exist. Given the heterogeneity within each Pacific Islander subgroup studied, Pacific Islanders should ideally be disaggregated when designing such future research, policy and other public health interventions in order to be most effective.

\section{Additional file}

Additional file 1: Maternal outcomes. Diagnoses with respective ICD-9 codes. (DOCX $42 \mathrm{~kb}$ )

\section{Abbreviations}

AHRQ: Agency for Healthcare Research and Quality; aOR: Adjusted odds ratios; Cl: Confidence intervals; ICD-9: International Classification of Diseases, 9th Revision; HHIC: Hawaii Health Information Corporation;

PRAMS: Pregnancy Risk Assessment Monitoring System; US: United States. 


\section{Competing interests}

The authors declare that they have no competing interests.

\section{Authors' contributions}

AC conceived the study, participated in the design the study, performed the statistical analysis and drafted the manuscript. JM obtained the data and participated in the design of the study. EH participated in the design of the study and helped to perform the statistical analysis. BK helped to perform the statistical analysis and helped to draft the manuscript. TS participated in the design of the study, helped to perform the statistical analysis and helped to draft the manuscript. All authors read and approved the final manuscript.

\section{Author's information}

$\mathrm{AC}, \mathrm{MD} / \mathrm{MPH}$, is an Assistant Professor at the University of Hawaii, Department of Obstetrics, Gynecology and Women's Health.

$\mathrm{EH}, \mathrm{DC} / \mathrm{PhD}$, is a Professor at the University of Hawaii, Office of Public Health Studies, University of Hawaii.

$\mathrm{JM}, \mathrm{PhD}$, is the Vice President and COO of the Hawaii Health Information Corporation.

$\mathrm{BK}, \mathrm{MD} / \mathrm{MPH}$, is an Associate Professor at the University of Hawaii, Department of Obstetrics, Gynecology and Women's Health.

TS, is an Associate Professor at the University of Hawaii, Office of Public Health Studies, University of Hawaii.

\section{Availability of data and materials}

Not applicable

\section{Acknowledgements}

This project was partially supported by Agency for Healthcare Research and Quality (AHRQ) grant R21 S021903.

\section{Author details}

'Department of Obstetrics, Gynecology and Women's Health, University of Hawaii, 1319 Punahou Street Suite \#824, Honolulu, HI 96826, USA. ${ }^{2}$ Office of Public Health Studies, University of Hawaii, 1960 East-west Road, Biomed D-204, Honolulu, HI 96822, USA. ${ }^{3}$ Hawaii Health Information Corporation, 733 Bishop Street, Suite 1870, Honolulu, HI 96813, USA.

\section{Received: 14 April 2015 Accepted: 25 September 2015}

\section{Published online: 05 October 2015}

\section{References}

1. US Census Bureau: 2012 Facts for Features: Asian/Pacific American Heritage Month: May 2012. Accessed Dec 2012. https://www.census.gov/newsroom/ releases/pdf/cb12ffo9_asian.pdf

2. Lu MC, Halfon N. Racial and ethnic disparities in birth outcomes: a life-course perspective. Matern Child Health J. 2003;7(1):13-30

3. Bryant AS, Worjoloh A, Caughey AB, Washington AE. Racial/ethnic disparities in obstetric outcomes and care: prevalence and determinants. Am J Obstet Gynecol. 2010;202(4):335-43.

4. Harris P, Jones N. We the People: Pacific Islanders in the United States. Census 2000 Brief CENSR-26. Washington, DC: US Census Bureau; 2005.

5. Shen JJ, Tymkow C, MacMullen N. Disparities in maternal outcomes among four ethnic populations. Ethn Dis. 2005;15(3):492-7.

6. Cabacungan ET, Ngui EM, McGinley EL. Racial/ethnic disparities in maternal morbidities: a statewide study of labor and delivery hospitalizations in Wisconsin. Matern Child Health J. 2012;16(7):1455-67.

7. Creanga AA, Bateman BT, Kuklina EV, Callaghan WM. Racial and ethnic disparities in severe maternal morbidity: a multistate analysis, 2008-1010. Am J Obstet Gynecol. 2014;210:435. e1-8.

8. Rao AK, Daniels K, El-Sayed YY, Moshesh MK, Caughey AB. Perinatal outcomes among Asian American and Pacific Islander women. Am J Obstet Gynecol. 2006;195(3):834-8.

9. Le LT, Kiely JL, Schoendorf KC. Birthweight outcomes among Asian American and Pacific Islander subgroups in the United States. Int J Epidemiol. 1996;25(5):973-9.

10. Schempf AH, Mendola P, Hamilton BE, Hayes DK, Makuc DM. Perinatal Outcomes for Asian, Native Hawaiian, and other Pacific Islander mothers of single and multiple race/ethnicity: California and Hawaii, 2003-2005. Am J Public Health. 2010;100(5):877-87.
11. Wong LF, Caughey AB, Nakagawa S, Kaimal AJ, Tran SH, Cheng YW. Perinatal outcomes among different Asian-American subgroups. Am J Obstet Gynecol. 2008;199(4):382.e1-e6.

12. Ekeroma AJ, Craig ED, Stewart AW, Manetll CD, Mitchell EA. Ethnicity and birth outcome: New Zealand trends 1980-2001: Part 3, Pregnancy outcomes for Pacific women. Aust N Z J Obstet Gynaecol. 2004;44(6):541-4.

13. Tsitas M, Schmid BC, Oehler MK, Tempfer CB. Macrosomic and low birth weight neonates in Pacific Islanders from Samoa: a case-control study. Arch Gynecol Obstet. 2015 Jun 5. [Epub ahead of print].

14. Landon MB, Gabbe SG. Gestational diabetes mellitus. Obstet Gynecol. 2011;118(6):1379-93.

15. Sibai BM. Hypertensive disorders of pregnancy: the United States perspective. Curr Opin Obstet Gynecol. 2008;20(2):102-6.

16. Committee on Practice Bulletins-Obstetrics. Practice bulletin 130: prediction and prevention of preterm birth. Obstet Gynecol. 2012;120(4):964-73.

17. Penn Z, Ghaem-Maghami S. Indications for caesarean section. Best Pract Res Clin Obstet Gynaecol. 2001;15(1):1-15.

18. ACOG. Practice bulletin \#54: vaginal birth after previous cesarean. Obstet Gynecol. 2004;104(1):203-12.

19. Goldenberg RL, Culhane JF. Low birth weight in the United States. Am J Clin Nutr. 2007:85(2):584S-90.

20. Walsh JM, McAuliffe FM. Prediction and prevention of the macrosomic fetus. Eur J Obstet Gynecol Reprod Biol. 2012;162(2):125-30.

21. Healthcare Cost and Utilization Project State Inpatient Database Documentation. HCUP, Agency for Healthcare Research and Quality, 2007. Available at: http://www.hcup-us.ahrq.gov/overview.jsp. Accessed Dec 2012.

22. Hospital Inpatient Data, 2010-2011. Honolulu, HI: Hawaii Health Information Corporation; 2011. http://hhic.org/inpatient-data.asp. Accessed Dec 2012.

23. Schimmel MS, Bromiker R, Hammerman C, Chertman L, loscovich A, Granovsky-Grisaru S, et al. The effects of maternal age and parity on maternal and neonatal outcome. Arch Gynecol Obstet. 2015;4:793-8.

24. Laopiboon M, Lumbiganon $\mathrm{P}$, Intarut $\mathrm{N}$, et al. Advanced maternal age and pregnancy outcomes: a multicountry assessment. BJOG. 2014;121 Suppl 1:49-56.

25. Ganchimeg T, Ota E, Morisaki N, et al. Pregnancy and childbirth outcomes among adolescent mothers: a World Health Organization multicountry study. BJOG. 2014;121 Suppl 1:40-8. doi:10.1111/1471-0528.12630.

26. Dang BN, Van Dessel L, Hanke J, et al. Birth outcomes among low-income women-documented and undocumented. Perm J. 2011;15(2):39-43.

27. Stewart AL, Dean ML, Gregorich SE, et al. Race/ethnicity, socioeconomic status and the health of pregnant women. J Health Psych. 2007;12(2):285-300.

28. Weck RL, Paulose T, Flaws JA. Impact of environmental factors and poverty on pregnancy outcomes. Clin Obstet Gynecol. 2008;51(2):349-59.

29. Kozhimannil KB, Hung P, Prasad S, Casey M, Moscovice I. Rural-urban differences in obstetrics care, 2002-2010, and implications for the future. Med Care. 2014;52(1):4-9.

30. American College of Obstetricians and Gynecologists. Committee Opinion 429, March 2009. Health disparities for rural women.

31. Kaiser Family Foundation: How will the Uninsured in Hawaii Fare under the Affordable Care Act. http://kff.org/health-reform/fact-sheet/state-profilesuninsured-under-aca-hawaii/ (2014). Accessed April 2015.

32. Yasmeen S, Romano PS, Schembri ME, Keyzer JM, Gilbert WM. Accuracy of obstetric diagnoses and procedures in hospital discharge data. Am J Obstet Gynecol. 2006;194(4):992-1001.

33. Roberts CL, Bell JC, Ford JB, Hadfield RM, Algert CS, Morris JM. The accuracy of reporting of the hypertensive disorders of pregnancy in population health data. Hypertens Pregnancy. 2008;27(3):285-97.

34. JMP, Version 11.1.1. SAS Institute Inc., Cary, NC, 1989-2011.

35. IBM Corp. IBM SPSS Statistics for Windows, Version 21.0. Armonk, NY: IBM Corp; 2012.

36. Sibai BM. Chronic hypertension in pregnancy. Obstet Gynecol. 2002;100(2):369-77.

37. American College of Obstetricians and Gynecologists, Task Force on Hypertension in Pregnancy. Hypertension in Pregnancy. Report of the American College of Obstetricians and Gynecologists' Task Force on Hypertension in Pregnancy. Obstet Gynecol. 2013;122(5):1122-31.

38. Pregnancy outcomes in the Diabetes Control and Complications Trial. Am J Obstet Gynecol. 1996;174(4):1343-53.

39. Pridijian G. Pregestational diabetes. Obstet Gynecol Clin North Am. 2010;37(2):143-58.

40. Centers for Disease Control and Prevention (CDC). Maternal, pregnancy, and birth characteristics of Asians and Native Hawaiians/Pacific Islanders-King 
County, Washington, 2003-2008. MMWR Morb Mortal Wkly Rep. 2011;60(7):211-3.

41. Chang AL, Soon R, Kaneshiro B. The prevalence of gestational diabetes among Micronesians in Honolulu. Hawaii Med J. 2010;69(5 Suppl 2):4-6.

42. Blomberg M. Maternal obesity, mode of delivery, and neonatal outcome. Obstet Gynecol. 2013;122(1):50-5.

43. Zeng X, Hayes D, Shor R, Feigal D, Roberson E, Fuddy L. Preconception Overweight/Obesity and Pregnancy Fact Sheet. Honolulu, HI: Hawaii Department of Health, Family Health Services Division; 2010.

44. Shek D, Yamada S. Health care for Micronesians and constitutional rights. Hawaii Med J. 2011;70(11 Suppl2):4-8.

45. Andrade N, McDermott J, editors. People and Cultures in Hawaii: The Evolution of Culture and Ethnicity. Honolulu, H: The University of Hawaii Press; 2011.

46. Park CB, Braun KL, Horiuchi BY, Tottori C, Onaka AT. Longevity disparities in multiethnic Hawaii: an analysis of 2000 life tables. Public Health Rep. 2009;124:579-84.

47. Eworuke E, Hampp C, Saiti A, Winterstein AG. An algorithm to identify preterm infants in administrative claims data. Pharmacoepidemiol Drug Saf. 2012;21(6):640-50.

48. Hoffman SD, Maynard RA, editors. Kids Having Kids: Economic Costs and Social Consequences of Teen Pregnancy. 2nd ed. Washington, DC: Urban Institute Press; 2008.

49. McCracken KA, Loveless M. Teen pregnancy: an update. Curr Opin Obstet Gynecol. 2014;26(5):355-9.

50. Fraser AM, Brockert JE, Ward RH. Association of young maternal age with adverse reproductive outcomes. N Eng J Med. 1995;332(17):1113-7.

51. Althabe F, Moore $J$, Gibbons $L$, et al. Adverse maternal and perinatal outcomes in adolescent pregnancies: the global Network's maternal newborn health registry study. Reprod Heaalth. 2015;12 Suppl 2:s8. Epub 2015 Jun 8.

52. Hagiwara MK, Yamada S, Tanaka W, Ostrowski DM. Litigation and Community Advocacy to Ensure Health Access for Micronesian Migrants in Hawaii. J Health Care Poor Underserved. 2015;26(2 Suppl):137-45.

53. McElfish PA, Hallgren E, Yamada S. Effect of US health policies on health care access for Marshallese migrants. Am J Public Health. 2015;105(4):637-43.

54. McCubbin LD, Antonio M. Discrimination and obesity among Native Hawaiians. Hawaii J Med Public Health. 2012;71(12):346-52.

\section{Submit your next manuscript to BioMed Central and take full advantage of:}

- Convenient online submission

- Thorough peer review

- No space constraints or color figure charges

- Immediate publication on acceptance

- Inclusion in PubMed, CAS, Scopus and Google Scholar

- Research which is freely available for redistribution 